\title{
Health-related quality of life of the elderly with cancer in adjuvant treatment
}

\author{
Qualidade de vida relacionada à saúde de idosos com câncer em tratamento adjuvante
}

\author{
Calidad de vida relacionada con la salud de ancianos con cáncer en tratamiento adyuvante
}

\author{
Bruna Francielle Toneti ${ }^{1}$, Juliana Maria de Paula ${ }^{1}$, Adriana Cristina Nicolussi ${ }^{2}$, Namie Okino Sawada ${ }^{1}$
}

This study aimed at identifying changes in the quality of life of older people with cancer and characterizing the socio-demographic, clinical and therapeutic data, associating them with domains of health-related quality of life. This is a cross-sectional study, conducted in a private clinic in Ribeirão Preto, Brazil, from August 2012 to July 2013. It was carried out with 21 elderly patients with cancer and in adjuvant treatment. The instrument Quality of Life Questionnaire Core-30 (QLQ-C30) and a socio-demographic, clinical and therapeutic instrument were used to collect data which were then analyzed by the Statistical Package for Social Science software. The results showed that the general quality of life was satisfactory (average $=69.04$ ), the main affected domains were emotional function, social function, cognitive function, financial difficulties, fatigue, nausea and vomiting, dyspnea, and insomnia. The disease and the treatment interfere with the lives of the elderly and affect their health-related quality of life.

Descriptors: Quality of Life; Elderly; Oncologic Nursing; Nursing.

Este estudo teve os objetivos de identificar alterações na qualidade de vida de idosos com câncer e caracterizar os dados sociodemográficos, clínicos e terapêuticos, associando-os aos domínios de qualidade de vida relacionada à saúde. Trata-se de um estudo transversal, desenvolvido em uma clínica particular de Ribeirão Preto, Brasil, de agosto de 2012 a julho de 2013. Foi realizado com 21 idosos com câncer em tratamento adjuvante, sendo utilizado na coleta de dados o instrumento Quality of Life Questionnaire Core-30 (QLQ-C30) e um instrumento sociodemográfico, clínico e terapêutico. Os dados foram analisados pelo software Statistical Package for Social Science. Os resultados mostraram que a qualidade de vida geral foi considerada satisfatória (média = 69,04), os principais domínios afetados foram função emocional, social, cognitiva, dificuldades financeiras, fadiga, náuseas e vômitos, dispneia e insônia. A doença e o tratamento interferem na vida dos idosos e prejudicam a qualidade de vida relacionada à saúde.

Descritores: Qualidade de Vida; Idoso; Enfermagem Oncológica; Enfermagem.

Los objetivos del estudio fueron identificar cambios en la calidad de vida de ancianos con cáncer, caracterizar datos sociodemográficos, clínicos y terapéuticos y asociarlos con los dominios de calidad de vida relacionada con la salud. Estudio transversal, desarrollado en una clínica privada de Ribeirão Preto, SP, Brasil, de agosto de 2012 a julio de 2013. Se llevó a cabo con 21 ancianos con cáncer en tratamiento adyuvante, en que se utilizó el instrumento Quality of Life Questionnaire Core-30 (QLQ-C30) y un instrumento sociodemográfico, clínico y terapéutico. El software Statistical Package for Social Science analizó los datos. Los resultados señalaron que la calidad de vida en general fue satisfactoria (media $=69,04$ ), los principales dominios afectadas fueron función emocional, social, cognitiva, dificultades financieras, fatiga, náuseas y vómitos, disnea e insomnio. La enfermedad y el tratamiento interfieren en la vida de ancianos y perjudican la calidad de vida relacionada con la salud. Descriptores: Calidad de Vida; Ancianos; Enfermería Oncológica; Enfermería.

\footnotetext{
${ }^{1}$ Escola de Enfermagem de Ribeirão Preto, Universidade de São Paulo. Ribeirão Preto, SP, Brazil.

${ }^{2}$ Hospital das Clínicas da Faculdade de Medicina, Ribeirão Preto, SP, Brazil.

Corresponding author: Namie Okino Sawada

Av. dos Bandeirantes, 3900. Cidade Universitária, CEP: 14040-902. Ribeirão Preto, SP, Brazil. E-mail: sawada@eerp.usp.br
} 


\section{Introduction}

Cancer is a word used to name a set of diseases that affect various body parts. This disease is known to have an abnormal cell proliferation in the body whose cells can spread to various organs by a process called metastasis which is responsible for most cancer deaths ${ }^{(1)}$.

For 2014 in Brazil, the occurrence of approximately 576,000 new cases of cancer has been estimated, evidencing the problem of the disease in the country. Except in cases of non-melanoma skin, the highest occurring cancer types are prostate, lung, colon and rectum, and stomach for males, and breast, cervix, colon and rectum, and lung for females. This increased incidence of non-transmissible diseases in the country has been occurring more in the aging population, a process called epidemiological transcription ${ }^{(2)}$.

Aging is a normal, dynamic process, and involves losses in biological, socio-emotional and political planning reflecting on life expectancy, morbidity, premature mortality, disability and poor quality of $\operatorname{life}^{(3)}$, and currently non-communicable chronic diseases have affected many elderly, affecting the entire process. The elderly can also have comorbidities that should be considered during chemotherapy; they may be worsened by the treatment and make it a dependent activity in their daily life, negatively influencing their quality of life ${ }^{(4)}$.

This age group then becomes a group of attention since unlike younger patients, radical cancer treatment (associated surgery or not, adjuvant treatment and chemo radiation) for the elderly has shown to be debatable as the symptoms of treatment significantly interfere in their Health-Related Quality of Life.

So the Health-Related Quality of Life of the elderly is complex; it is necessary to evaluate various fields, especially those related to health problems and the effects of treatment which can lead the elderly to experience deficits in many aspects of their lives.

Often we find the use of terms Quality of Life and Health-Related Quality of Life. The term Quality of Life is used as a general concept, since the term Health-Related Quality of Life is often used in the literature in the area of health, which implies more directly associated aspects to disease and/or the health interventions.

As defined in the Quality of Life Group set up by the World Health Organization, quality of life is "an individual's perception of their position in life in the context of culture and value systems in which they live and in relation to their goals, expectations, standards and concerns"(5:1405). This broad definition considers the perception of the individual as a whole, from their physical health and psychological state, to social relations and personal beliefs ${ }^{(5)}$.

With the evolution of Medicine and the resulting increase in life expectancy, studies of the elderly have increased because they understood that they were not going to live longer, but live with a better quality of life. According to the World Health Organization, the quality of life in old age is having health the highest level possible in the four aspects of human life: physical, social, psychological and spiritual ${ }^{(6)}$, and the emerging need to study the quality of life of patients with increased survival due to cancer treatment.

The term Health-Related Quality of Life also arises which evaluates the quality of life in situations of disease or treatment; it is the individual's perception of their health status or perceived health status ${ }^{(7)}$.

Although some elderly patients with cancer demonstrate good living with the disease, it can be perceived from some of their statements that they suffer living with cancer, probably due to their outlook on life, beliefs and fears related to the disease and treatment which highlights the importance of developing nursing care to assist them during this conflict ${ }^{(8)}$. The nurse can perform interventions to serve as complementary therapy to chemotherapy which, besides having positive effects on the Health-Related Quality of Life, are low cost and have no side effects such as relaxation sessions and physical activity.

This study aimed to identify changes in HealthRelated Quality of Life of older people with cancer 
and characterize the socio-demographic, clinical and therapeutic data, relating them to the domains of Quality of Life Related to Health. References in the literature were used in order to allow for the identified evidence to be assessed and to assist in nursing care that meets the needs of these patients, and in doing so to boost their Health-Related Quality of Life during this process, as this age group is very different in regards to care and treatment compared to other groups.

\section{Methods}

This is a descriptive, cross-sectional study of a quantitative approach, developed at a private clinic in Ribeirão Preto-SP from August 2012 to July 2013. The sample consisted of 21 elderly patients with adjuvant cancer treatment. Inclusion criteria were: people aged greater than or equal to 60 years, diagnosed with cancer, treated at a private clinic and in treatment. Patients who had any cognitive deficit that could hinder their understanding and/or participation in the study or interviews were excluded. The assessment of cognitive impairment was performed by simple questions such as the date of the month or day of the week, their address, age and others.

An identification questionnaire to collect demographic data containing the following variables was used: gender, age, marital status, origin, profession/occupation, level of education and religion; also the following clinical and therapeutic data: diagnosis, implementation and type of surgery; receiving radiotherapy; receiving, protocol and side effects of chemotherapy.

Through interviews, data on the Health-Related Quality of Life were collected using the Core-30 Quality of Life Questionnaire (QLQ-C30) instrument developed by the European Organization for Research and Treatment group of Cancer (EORTC).

The QLQ-C30 third version questionnaire is used for assessing Health-Related Quality of Life, and has been properly validated for Brazilian culture $^{(9)}$ for exclusive use in cancer patients. Its use is multidimensional; addressing various aspects of cancer such as side effects of treatment and symptoms of disease, social relations, psychological distress, functional capacity, financial difficulties, general health and quality of life $\mathrm{e}^{(10)}$.

The answers obtained from the QLQ-C30 questionnaire produce scores of the evaluated scales which are converted to values from 0 to 100 . Higher values on the functional scale and range of general health and quality of life symbolize a good quality of life. Those who are high in scales and items of symptoms symbolize a poor quality life as a high score is a larger number of symptoms present.

Data were analyzed using the Statistical Package for Social Science, version 15.0, and the Cronbach's Alpha internal consistency test was also performed to verify the reliability of the instrument. The calculation of the average and standard deviation for descriptive analysis and ANOVA parametric test were also conducted to compare the domains of the Health-related quality of life instrument with socio-demographic, clinical and therapeutic data.

The research project was approved by the Ethics and Research of the Ribeirão Preto School of Nursing Committee of the University of São Paulo, under the Protocol 134375/ 2012-2, and maintained secrecy as to the identity of patients in accordance with Resolution 466/2012 of the National Health Council.

\section{Results}

As for the socio-demographic characteristics of the 21 patients interviewed, all participants were from Ribeirão Preto (81\%) and nearby areas (19\%), eight (38.1\%) males and 13 (61.9\%) were female, predominantly aged between 60 and 79 years (85.7\%). Regarding marital status and occupation, most were married (81\%) and retired (76.2\%). The item for level of education shows us that most of the participants attended higher education (52.4\%), while 14.3\% finished high school and $33.3 \%$ had finished elementary 
school. Finally, $76.2 \%$ were Catholic, $14.3 \%$ were spiritualists, $4.8 \%$ were evangelical and $4.8 \%$ Buddhist.

Table 1 shows the clinical and therapeutic characteristics of the patients. It can be observed that most diagnoses were breast cancer (33.3\%) and stomach cancer $(33.3 \%)$, and $47.6 \%$ of patients showed metastasis. $81 \%$ underwent surgery, and $38.1 \%$ reported they had or were having radiotherapy.

Table 1- Clinical and therapeutic characteristics of elderly patients with cancer $(n=21)$

\begin{tabular}{lc}
\hline Variables & $\mathbf{n}(\%)$ \\
\hline Diagnostic (Type of cancer) & $7(33.3)$ \\
Breast & $1(4.8)$ \\
Prostate and testicular & $4(19.0)$ \\
Intestinal & $7(33.3)$ \\
Gastric & $1(4.8)$ \\
Kidney & $1(4.8)$ \\
Pulmonary & \\
Underwent surgery & $17(81.0)$ \\
Yes & $4(19.0)$ \\
No & \\
Type of surgery (Removal) & $5(29.4)$ \\
Tumor/ lumps and/or adjacent & $4(23.5)$ \\
Partial of the affected organ and/or adjacent & $6(35.3)$ \\
Total of the affected organ and/or adjacent & $2(11.8)$ \\
Patient could not inform & $10(47.6)$ \\
Underwent radiotherapy & $1(4.8)$ \\
Yes & \\
No & $13(38.1)$ \\
Metastases & $13(61.9)$ \\
Yes & $10(47.6)$ \\
Gaste effects & $1(52.4)$ \\
\hline & \\
Gastroingtrointestinal + physical + emotional & \\
\hline
\end{tabular}

Regarding the side effects of chemotherapy, the largest proportion (47.6\%) of patients reported gastrointestinal effects associated with physical effects, such as nausea, vomiting, constipation, diarrhea, sickness in general, weakness, drowsiness, insomnia and pain (table 1).

\section{Health-related quality of life}

Regarding the sample, the Cronbach alpha coefficient obtained was 0.81 , demonstrating the reliability of the instrument to the sample.

Table 2 shows the mean and standard deviation of the functional scales, general health status, symptoms and QLQ-C30 items. The health-related quality of life (HRQOL) scored an average of 69.04, which shows that patients consider their quality of life after the start of cancer treatment as satisfactory, since the closer to the maximum 100 score, the better the Health-Related Quality of Life. Scores of functional scales also confirmed this result, as there were more than 50 within the range of 0 to 100 considered for this assessment.

As for the physical, cognitive and social functions, Table 2 shows that the means ranged from 64.28 to 76.19 and the scale of role functioning averaged 72.22 , which also showed a satisfactory level. However, for the emotional function assessed by questions 21-24 of the instrument, the average was 67.46 which revealed that patients reported feeling depressed, tense, angry and worried. 
Table 2 - Average and standard deviation of the scales and symptoms of QLQ-C30 instrument obtained in elderly with cancer

\begin{tabular}{lc}
\hline Scales and Symptoms & Average (DP) \\
\hline General Health Status (GHS/QOL) & $69.04(16.90)$ \\
Physical functioning (PF) & $70.79(20.49)$ \\
Role performance (RP) & $72.22(27.04)$ \\
Emotional functioning (EF) & $67.46(24.13)$ \\
Cognitive functioning (CF) & $76.19(25.03)$ \\
Social functioning (SF) & $64.28(36.24)$ \\
Fatigue (FAT) & $35.23(31.20)$ \\
Nausea/vomiting (NAV) & $11.90(24.23)$ \\
Pain (P) & $24.60(31.00)$ \\
Dyspnea (DYS) & $4.76(15.93)$ \\
Insomnia (INS) & $25.39(23.34)$ \\
Appetite loss (AL) & $39.68(38.89)$ \\
Constipation (CON) & $26.98(32.69)$ \\
Diarrhea (DIA) & $26.98(35.92)$ \\
\hline Sinancial difficulties (FDI) & $14.28(24.87)$ \\
\hline
\end{tabular}

On the scale of symptoms, appetite loss had the highest average (39.68), followed by fatigue (35.23), constipation and diarrhea (26.98), insomnia (25.39), pain (24.60), nausea and vomiting (11.90) and dyspnea (4.76). For financial difficulties, the average was 14.28 , which showed that cancer treatment in a private clinic brought financial difficulties to patients since some health plans do not fully cover the treatment.
Table 3 - Scales distribution of QLQ-C30, socio-demographic data and statistics on the elderly with cancer

\begin{tabular}{|c|c|c|c|c|c|}
\hline \multirow{2}{*}{$\begin{array}{l}\text { Scale } \\
\mathrm{EF}\end{array}$} & \multicolumn{2}{|l|}{ Variables } & Average & $\begin{array}{l}\text { Standard } \\
\text { deviation }\end{array}$ & $\begin{array}{c}P \\
\text { value }\end{array}$ \\
\hline & \multirow[t]{4}{*}{ Religion } & Catholic & 70.83 & 19.48 & \multirow[t]{4}{*}{0.021} \\
\hline & & Evangelist & ---- & ---- & \\
\hline & & Spiritualist & 66.67 & 22.04 & \\
\hline & & Buddhist & 83.34 & ---- & \\
\hline \multirow[t]{2}{*}{ FDI } & \multirow[t]{2}{*}{ City } & Ribeirão Preto & 7.84 & 18.74 & \multirow[t]{2}{*}{0.010} \\
\hline & & Other cities & 41.66 & 31.91 & \\
\hline \multirow[t]{3}{*}{$\mathrm{CF}$} & \multirow[t]{3}{*}{ Marital status } & Single & 33.34 & 0.00 & \multirow[t]{3}{*}{0.022} \\
\hline & & Married & 79.41 & 22.45 & \\
\hline & & Widowed & 91.67 & 11.78 & \\
\hline \multirow[t]{3}{*}{ FDI } & \multirow[t]{3}{*}{ Marital status } & Single & 33.33 & 47.13 & \multirow[t]{3}{*}{0.030} \\
\hline & & Married & 7.84 & 18.74 & \\
\hline & & Widowed & 49.99 & 23.56 & \\
\hline \multirow[t]{3}{*}{ INS } & \multirow[t]{3}{*}{ Scholarship } & $\begin{array}{l}\text { Complete Middle } \\
\text { School }\end{array}$ & 55.55 & 19.24 & \multirow[t]{3}{*}{0.038} \\
\hline & & $\begin{array}{l}\text { Complete High } \\
\text { School }\end{array}$ & 23.80 & 25.19 & \\
\hline & & $\begin{array}{l}\text { Higher } \\
\text { education }\end{array}$ & 18.18 & 17.40 & \\
\hline
\end{tabular}

To compare the results of the QLQ-C30 scales with socio-demographic data (Table 3) and clinical and therapeutic data (Table 4), ANOVA was performed considering the $\mathrm{P}$ value less than or equal to 0.05 as statistically significant. 
Table 4 - Scale distribution of QLQ-C30, clinical and therapeutic variables of elderly patients with cancer

\begin{tabular}{|c|c|c|c|c|}
\hline Scale & Variables & Average & $\begin{array}{l}\text { Standard } \\
\text { deviation }\end{array}$ & $\begin{array}{c}P \\
\text { value }\end{array}$ \\
\hline \multirow[t]{7}{*}{ NAV } & Diagnostic & & & \\
\hline & Breast cancer & 2.38 & 6.29 & 0.019 \\
\hline & Prostate cancer & 83.33 & ---- & \\
\hline & Intestinal cancer & 4.16 & 8.33 & \\
\hline & Gastric cancer & 19.04 & 27.93 & \\
\hline & Kidney cancer & 0.00 & ---- & \\
\hline & Pulmonary cancer & 0.00 & ---- & \\
\hline \multirow[t]{7}{*}{ DYS } & Diagnostic & & & \\
\hline & Breast cancer & 4.76 & 12.59 & 0.000 \\
\hline & Prostate cancer & 66.66 & ---- & \\
\hline & Intestinal cancer & 0.00 & 0.00 & \\
\hline & Gastric cancer & 0.00 & 0.00 & \\
\hline & Kidney cancer & 0.00 & ---- & \\
\hline & Pulmonary cancer & 0.00 & ---- & \\
\hline \multirow[t]{6}{*}{$\mathrm{EF}$} & Type of surgery & & & \\
\hline & No surgery & 75.00 & 20.41 & 0.028 \\
\hline & $\begin{array}{l}\text { Removal of tumor/ lumps and/or } \\
\text { adjacent }\end{array}$ & r 40.00 & 27.26 & \\
\hline & $\begin{array}{l}\text { Partial removal of the affected } \\
\text { organ and/or adjacent }\end{array}$ & 72.92 & 17.17 & \\
\hline & $\begin{array}{l}\text { Total removal of the affected } \\
\text { organ and/or adjacent }\end{array}$ & 73.61 & 14.35 & \\
\hline & Patient could not inform & 91.67 & 0.00 & \\
\hline \multirow[t]{6}{*}{ INS } & Type of surgery & & & \\
\hline & No surgery & 24.99 & 31.91 & 0.046 \\
\hline & $\begin{array}{l}\text { Removal of tumor/lumps and/ } \\
\text { or adjacent }\end{array}$ & 46.66 & 18.25 & \\
\hline & $\begin{array}{l}\text { Partial removal of the affected } \\
\text { organ and/or adjacent }\end{array}$ & 8.33 & 16.66 & \\
\hline & $\begin{array}{l}\text { Total removal of the affected } \\
\text { organ and/or adjacent }\end{array}$ & 27.77 & 13.60 & \\
\hline & Patient could not inform & 0.00 & 0.00 & \\
\hline \multirow[t]{3}{*}{ GHS } & Radiotherapy & & & \\
\hline & Yes & 53.12 & 13.31 & 0.000 \\
\hline & No & 78.84 & 9.98 & \\
\hline \multirow[t]{3}{*}{ NAV } & Radiotherapy & & & \\
\hline & Yes & 24.99 & 35.63 & 0.049 \\
\hline & No & 3.84 & 7.30 & \\
\hline \multirow[t]{6}{*}{ FAT } & Side effects & & & \\
\hline & Asymptomatic & 6.66 & 14.90 & 0.039 \\
\hline & Gastrointestinal effects & 10.00 & ---- & \\
\hline & Physical effects & 54.66 & 27.66 & \\
\hline & Gastrointestinal + physical effects & 54.66 & 28.93 & \\
\hline & $\begin{array}{l}\text { Gastrointestinal + physical + } \\
\text { emotional effects }\end{array}$ & 20.00 & ---- & \\
\hline
\end{tabular}

Regarding chemotherapy protocols, a statistical significance (0.049) was observed for the protocols of Fulvestrant + Zoledronic acid (6x6 months); Cisplatin + Gemcitabine; Torisel; Bevacizumab + Folinic Acid + 5-Fluorouracil; Folfirinox (+ Zotecan Eloxatina Fauldfluor +); Capecitabine + Cyclophosphamide + Avastin; Erbitux; Carboplatin + Etoposide; Carboplatin + 5-fluorouracil; cisplatin; Sandostatin; Carboplatin + Paclitaxel; 5-Fluorouracil + Camptosar + Oxaliplatin with Role functioning scale and statistically significant difference (0.026) of the same chemotherapy protocols for the Social Functioning scale of the QLQ-C30 instrument.

As for statistically significant associations of the QLQ-C30 scales with demographic data, statistically significant associations were found between religion and emotional functioning (EF); city and financial difficulties (FDI); level of education with insomnia (INS) and marital status with Cognitive Function (CF) and Financial Difficulties (FDI).

\section{Discussion}

The socio-demographic characteristics of the sample describe the studied age group as being affected by cancer in the age group between 60 and 79 years, with higher incidence in females. It also shows that the majority of the sample was made up of retirees, Catholics, married and with a high degree of education.

This research data corroborates information from another research, also conducted in Ribeirão Preto $^{(10)}$, through which the QLQ-C30 assessed the Health-Related Quality of Life of cancer patients diagnosed with cancer receiving chemotherapy treatment at two public clinics.

In correlating Health-Related Quality of Life with sociodemographic data, several significant associations were found, such as high scores for spiritualist patients in emotional functioning, cognitive function for widowed patients and patients with a low level of education for the symptom of insomnia. Pa- 
tients coming from the data collection district region and widowed patients reported greater financial difficulties during treatment.

The cancer patients seek religion as a way of coping with the disease in order to minimize suffering and achieve greater hope for cure with treatment ${ }^{(11)}$. Associated with the therapy, spiritual treatment is sought by them in order to seek a balance between emotions during the healing process as they report the belief that spiritual treatment assists and enhances their chances of curing the disease ${ }^{(12)}$. Also, religion has great influence on acceptance of the disease by the elderly who consider cancer as a divine $\operatorname{plan}^{(8)}$. It can be inferred that the result of better emotional function in the spiritualist patients is also due to that fact.

In relation to financial difficulties encountered by patients during treatment, the literature shows that this situation occurs because of the elderly and their families need to move from their cities to nearby cities with proper infrastructure required for therapy. Furthermore, although retirement provides financial autonomy of the elderly, it is not always enough to cover the expenses necessary for chemotherapy, which leads the elderly to depend on family aid ${ }^{(13)}$.

Symptoms of cancer treatment are one of the major difficulties faced by patients during treatment. Insomnia, for example, was described by this study to have significant associations to the level of education and type of surgery performed. This is a problem because in addition to involvement in daytime activities, its main consequences are fatigue and depression ${ }^{(14)}$. The hypothesis of depression as a contributor to the development of non-communicable chronic disease in old age is already being discussed, highlighting the importance of this association to elderly care during cancer treatment.

Other symptoms that had a significant association in this study were nausea and vomiting related to the diagnosis of Prostate Cancer and radiotherapy. These occur because they are common symptoms of irradiation and are described by studied patients as influential factors on their quality of life during treatment.

In relation to radiotherapy - one of the most suitable for elderly with cancer - and its significant association to the general health of the patients in this sample, other studies report that this treatment (associated with the disease) results in a reduced functional performance level and increased depression, which alters the quality of life of patients and hence their perception of their overall health ${ }^{(15-17)}$.

As for protocols, it was observed that patients who were taking Avastin + Folinic Acid + 5-Fluorouracil reported low scores for Role Functioning scale, and patients who used Etoposide + Carboplatin also reported low scores for the Social Functioning scale. These drugs have anti-tumor activity in several types of cancer, and promote the symptoms reported by patients such as nausea, diarrhea and fatigue which can substantiate the reported low scores for Role Functioning and Social Functioning scales because of the interference of these symptoms. Chemotherapy has important clinical association to the elderly's functional capabilities, while symptoms are related to treatment, most often to a reduction in capacity ${ }^{(18)}$.

Along the same lines, a study also noted that many older people undergoing chemotherapy had significant changes in their health due to the presence of fatigue. This relationship between chemotherapy and reducing social function can occur because of chemotherapy, often associated with fatigue, and causes an increased need for the patient to rest. This affects their performance in carrying out their usual social activities as before treatment ${ }^{(19)}$. For seniors with cancer, contact with other patients with the disease provides greater comfort and acceptance in the diagnosis, as they can share feelings and frustrations in relation to their common disease. This highlights the importance of social relationships for the elderly during this $\operatorname{period}^{(8)}$.

It was observed in this study that fatigue symptoms associated with higher scores to the side effects of the treatment, more particularly to gastrointestinal 
effects. Fatigue is the symptom most commonly reported by patients in adjuvant treatments for cancer, especially during radiotherapy and chemotherapy; it is related to feeling very tired and a reduction in carrying out daily activities. Generally, this symptom is described by patients reporting a lack of energy, fatigue, diminished interest in performing previously pleasurable activities, dyspnea, stress and loss of concentration $^{(18-20)}$. Fatigue in the present study was associated with less average overall health and quality of life, as it was the most frequently reported symptom by the patients.

As this is a cross-sectional study, the results should be evaluated by considering the limitations of this study. However, the data found statistically significant relationships to describe the scales of Emotional Functioning, Social Functioning, Cognitive Functioning, Financial Difficulties and symptoms such as fatigue, nausea and vomiting, dyspnea, and insomnia with quality of life and health of the patients, although the Health-Related Quality of Life has been considered satisfactory. Understanding these variables can enable interventions and nursing care related to the functions and symptoms during treatment, and should be strengthened in order to help improve the quality of life and health of elderly cancer patients in adjuvant treatment.

\section{Conclusion}

This study evaluates the Health-Related Quality of Life of elderly cancer patients in adjuvant treatment, showing that the average Health-Related Quality of Life conducted based on the QLQ-C30 instrument of the sample was 69.04 , and is therefore to be considered satisfactory. The results show that the domains of Quality of Life Related to Health affected were: emotional, social, and cognitive functioning, financial difficulties, fatigue, nausea and vomiting, dyspnea and insomnia, which were associated with religion, marital status, level of education and city of origin.

The results indicate that it is important to understand the variables associated to Health-Related Quality of Life of older people receiving cancer treatment, to be useful in assisting with care and nursing interventions, promoting better overall health and Health-Related Quality of Life within this population.

Similar studies are needed due to the rapid process of population aging. A nurse is the health professional who has the most interaction with people during the aging process, so it is essential to use tools that can indicate changes and meet health or personal situations that are more likely to change the quality of life. Thus, nurses can assist and provide a better quality of life for older people with cancer and assist in the rehabilitation process.

The restricted sample function was a study limitation and as such the results may not be widely generalized. Therefore, the development of longitudinal studies is suggested so that the changes of Health-Related Quality of Life over time can be assessed in order to gain a better understanding of the factors involved in the oncological treatment of the elderly.

\section{Acknowledgements}

To Eduardo Henrique Marinheiro, who directly participated in the completion of this research, without him the research would not have the same quality.

\section{Collaborations}

Toneti BF participated in the preparation, data collection, analysis and writing of the article. Paula JM participated in the collection and analysis of data. Nicolussi AC and Sawada NO participated in the critical revision of the article. 


\section{References}

1. World Health Organization. Health topics. Cancer. Fact sheets. What is cancer? [Internet]. 2013 [cited 2013 July 17]. Available from: http://www. who.int/mediacentre/factsheets/fs297/en/

2. Instituto Nacional de Câncer José Alencar Gomes da Silva. Estimativa 2014: Incidência de câncer no Brasil. [Internet]. 2011 [citado 2013 jul 20]. Disponível em: http://www2.inca.gov. $\mathrm{br} / \mathrm{wps} / \mathrm{wcm} / \mathrm{connect/agencianoticias/site+/}$ home+/noticias/2013/inca_ministerio_saude_ apresentam_estimativas_cancer_2014

3. Alencar MSS, Carvalho CMRG. O envelhecimento pela ótica conceitual, sociodemográfica e políticoeducacional: ênfase na experiência piauiense. Rev Interface. 2009; 13(29):435-44.

4. Fabrício VC. Tratamento oncológico no idoso. Rev Bras Med. 2011; 68(2):4-7.

5. The WHOQOL Group. The World Health Organization quality of life assessment (WHOQOL): position paper from the World Health Organization. Soc Sci Med. 1995; 41(10):1403-9.

6. Assis CL, Gomes JM, Zentarski LOF. Religiosidade e qualidade de vida na terceira idade: uma revisão bibliográfica a partir da produção científica. Rever. 2013; 13(2):119-48.

7. Fayers PM,Machin D. Quality oflife: the assessment, analysis and interpretation of patient-reported outcomes. Chichester: Wiley; 2007.

8. Soares LC, Santana MG, Muniz RM. O fenômeno do câncer na vida de idosos. Cienc Cuid Saúde. 2010; $9(4): 660-7$.

9. Franceschini J, Jardim JR, Fernandes ALG, Jamnik S, Santoro IL. Reproducibility of the Brazilian Portuguese version of the European Organization for Research and Treatment of Cancer Core Quality of Life Questionnaire used in conjunction with its lung cancer-specific module. J Bras Pneumol. 2010; 36(5):595-602.
10. Nicolussi AC, Sawada NO, Cardozo FMC, Andrade V, Paula JM. Health-related quality of life of cancer patients undergoing chemotherapy. Rev Rene. 2014; 15(1):132-40.

11. Guerrero GP, Zago MMF, Sawada NO, Pinto MH. Relação entre espiritualidade e câncer: perspectiva do paciente. Rev Bras Enferm. 2011; 64(1):53-9.

12. Aureliano WA. Terapias espirituais e complementares no tratamento do câncer: a experiência de pacientes oncológicos em Florianópolis (SC). Cad Saúde Coletiva. 2013; 21(1):18-24.

13. Visentin A, Lenardt MH. Therapeutic itinerary: oral history of elderly patients with cancer. Acta Paul Enferm. 2010; 23(4):486-92.

14. Rafihi-Ferreira RE, Soares MRZ. Insônia em pacientes com câncer de mama. Estud Psicol. 2012; 29(4):597-607.

15. Paula JM, Sonobe HM, Nicolussi AC, Zago MMF, Sawada NO. Symptoms of depression in patients with cancer of the head and neck undergoing radiotherapy treatment: a prospective study. Rev Latino-Am Enfermagem. 2012; 20(2):362-8.

16. Porter LS, Keefe FJ. Psychosocial issues in cancer pain. Curr Pain Headache Rep. 2011; 15(4):26370.

17. Mosher CE, Duhamel KN, Egert J, Smith MY. Selfefficacy for coping with cancer in a multiethnic sample of breast cancer patients: associations with barriers to pain management and distress. Clin J Pain. 2010; 26(3):227-34.

18. Hurria A, Li D, Hansen K, Patil S, Gupta R, Nelson C, et al. Distress in older patients with cancer. J Clin Oncol. 2009; 27(26):4346-51.

19. Mansano-Shlosser TC, Ceolim MF. Fadiga em idosos em tratamento quimioterápico. Rev Bras Enferm. 2014; 67(4):623-9.

20. Sawada NO, Paula JM, Sonobe HM, Zago MMF, Guerrero GP, Nicolussi AC. Depression, fatigue and health-related quality of life in head and neck cancer patients: a prospective study. Support Care Cancer. 2012; 20(11):2705-11. 